\title{
The Adoption of Computers by Australian General Practice - A Complex Adaptive Systems Analysis
}

\section{Christopher Pearce ${ }^{1,2 *}$}

${ }^{1}$ Director of Research, Inner East Melbourne Medicare Local, Australia

${ }^{2}$ Adjunct Associate Professor, Monash University, Australia

\begin{abstract}
The world is slowly moving to an E-Health environment. Computers are becoming an essential part of how health is delivered, just as they are a part of all other aspects of life. Yet the adoption of computers is patchy. In some jurisdictions it is the hospital sector that is highly computerized, and in others it is primary care. This paper examines the adoption of computers in general practice in Australia, and provides a theoretical explanation for the reasons general practices adopted computers, while hospitals did not. The application of Complex Adaptive Systems not only explains the computerization, but provides lessons for others in promoting computers in the health sector.
\end{abstract}

Keywords: Electronic health records; Computers in general practice; Change and adoption; Primary care; Complex adaptive systems

\section{Background}

Understanding the why behind change allows us to better plan and implements change in the future. For this reason the literature on change, and change management, is vast and never ending. Yet no particular model of change suits all situations, and no situation is perfectly suited to a particular change model. Theory construction about change varies from the personal to the structural and the sociological. Maslow's hierarchy of needs is an example of the first [1], structuration theory the second [2], and Habermas' theory of communicative action the third $[3,4]$. The use of social theory allows a deep understanding of the underlying social forces at work, with a view to applying those understandings to different settings.

This paper's aim is to take an established theory, Complex Adaptive Systems (CAS) and applying to a hitherto untheorised (but not unresearched) area, the adoption of computers in primary care. It uses as a case study the uptake of desktop clinical information systems (CIS) in Australia in the period 1995-2005, a period in which general practitioner computerization went from effectively nil to $100 \%$. What made many thousands of individual, unconnected practices adopt computers, and what might others learn from this? This paper will describe the principles of CAS, and then the adoption of computer systems within Australia, and then explore the linkages.

\section{Complex Adaptive Systems}

Isaac Newton was the first to propose that the natural world was like a great big clockwork entity, a place that can be broken down into constituent parts and problems analyzed successfully [5]. This 'machine like view', whilst popular during the age of enlightenment, has been inadequate to describe the many complexities of any society. Analyzing change as seen in the real world required new theories to be developed, and CAS is one of these and has been well established as a way of thinking about health [6]. CAS moves away from the view that organizations are like machines, and proposes a more nuanced view of organizational activity.

CAS suggests that it is the relationships between the parts that have significance, and any change must be related to the whole system, rather than the parts. Such a theory allows that the parts are selfmotivating, and are, or can be, responsive. At its most succinct, the principle underlying CAS theory is this: simple agents following simple rules [can] generate amazingly complex structures $[7,8]$.

An analogy to understand this is to look at the process of birds forming a flock. The traditional understanding is that there is a leader, a champion, and the birds are following the leader. Such 'champion' theory pervades change management theory as well. This theory suits the hierarchical model that dominates much management and hospital thinking. However, One study showed that flocking behaviour could be modeled using three simple rules for each individual bird in the flock [9]:

1. Each bird must maintain a minimum distance from other objects in the environment, including other birds.

2. Each bird must match velocities with other Birds in the neighbourhood.

3. Each bird must move towards the perceived centre of mass of the Birds in the neighbourhood.

When each Bird follows these rules, you get a flock. There is no leader, no overall plan, and no 'collective intention'. No individual bird necessarily understands the concept of the 'flock' of which it is part. Nevertheless, these rules, operating individually and at an entirely local level, are sufficient to produce globally coherent patterns that look as if someone, or at any rate something, is directing them. So, it is the relationships that exist between each bird, and the simple rules that apply, that create a complex, yet beautiful system. The central thesis is that complex systems consist of elements following simple rules, unaware of the complexity they are producing, and making no reference to any centralized blueprint. Yet complex systems they do produce.

In addition to these rules that the individual in the system follow is

${ }^{*}$ Corresponding author: Christopher Pearce, Associate Professor, Director of Research, Inner East Melbourne Medicare Local, 10 Lakeside Drive, East Burwood 3151, Australia, Tel: 8822 8844; Fax: 8822 8550; E-mail: chris.pearce@monash.edu

Received May 31, 2013; Accepted August 12, 2013; Published August 16, 2013

Citation: Pearce C (2013) The Adoption of Computers by Australian General Practice - A Complex Adaptive Systems Analysis. J Gen Pract 1: 121. doi: 10.4172/2329-9126.1000121

Copyright: (C) 2013 Pearce C. This is an open-access article distributed under the terms of the Creative Commons Attribution License, which permits unrestricted use, distribution, and reproduction in any medium, provided the original author and source are credited. 
the concept of attractors, external forces that can drive the individual elements of the system. These attractors can be structural, or moral, or ethical [10], a model that applies well in health. The combination of these often tacit rules and attractors allows the creation of a harmonious system independent of the motivations of the individual component.

\section{Australian General Practice}

Currently general practice is the most computerized part of the health sector, and contrasts quite markedly with the hospital sector that is not. $95 \%$ of GPs have a computer on their desk, and over $50 \%$ are effectively paperless [11]. Figure 1 (drawn from government data) shows that this change was fairly rapid and fairly recent. GPs use four clinical functions per consultation, with prescribing most common [12], and letter writing identified as the most time consuming. All use it for prescribing, and well over half are using it for recording of progress notes. $85 \%$ are using their computer to electronically generate a paper lab/radiology request, and receive the results of same electronically [11]. Health summaries, treatment plans, letters - all are part of the varied mix. By comparison, the hospital sector remains relatively noncomputerized, apart from administrative functions. This is despite quite significant local programs to computerize them.

Now, this penetration of computers is not unusual. Similar numbers exist in the UK, other parts of Europe [13], but not in North America, where penetration rates are probably as low as 25\% [14], and CIS's are much more prevalent in the hospital setting. In the UK, the National Health Service paid for and provided systems conformant to the national specifications. In the US, the 'meaningful use' program is only just starting to have effect [15].

Understanding the Australian Health care system is pivotal to understanding some of the later explanations. Australia has a health system with many funding streams and many focuses. For the most part, Australia has a fairly even balance between the private sector and the public sector. Australia is a federated political system, with some functions controlled by the federal government, and others by the states. Taxation is collected federally, but some of that is distributed to the states [16]. The states have carriage of funding the strong public hospital sector, and a much smaller community health sector. There is also a strong private hospital sector, and virtually all general practice is private practice. Private medical practice is underpinned by a federal universal health insurance scheme, called Medicare, that pays patients a rebate for visits to the doctor (or the doctor can accept as the full fee) [17]. People can also take out insurance for hospital costs. This variability is a factor in the different uptakes. But to get back to the theme of this paper, let us go back to general practice.

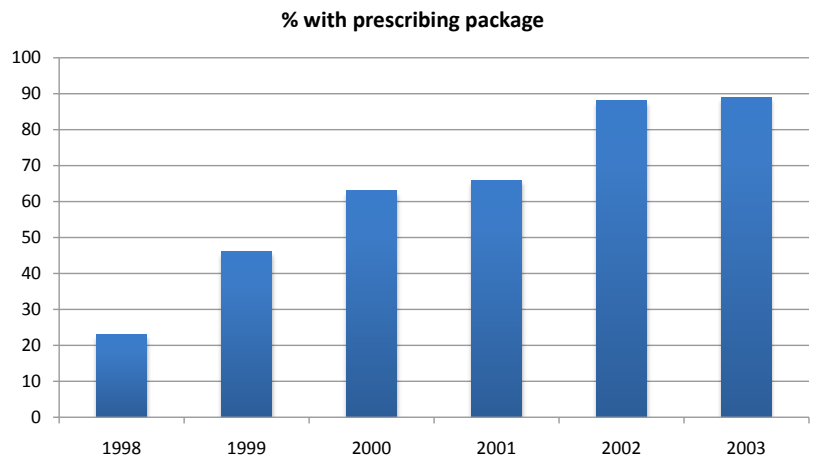

Figure 1: Adoption rates.
General practice is private practice, albeit one that attracts significant amounts of government subsidy, in the sense that Medicare usually pays a significant amount of a GPs income. Medicare pays about $70 \%$ of fees. This influences the levers by which the adoption of computers can be encouraged.

\section{Central Incentives}

From a system perspective, central government provided only a small amount of incentives to adopt. From 1998 to 2001 the federal government provided somewhere in the vicinity of AUD\$15M [18]. Looked at from the perspective of the overall health budget, and some of the sums spent on computerization in other jurisdictions, this represented a very small outlay. With the health budget in the many billions, this outlay is either $0.07 \%, 0.1 \%$ or $0.3 \%$ of outlay, depending on whether you use total health outlay, commonwealth outlay, or commonwealth outlay on general practice alone. In any of the cases, the money spent is miniscule.

This money was applied not as grants, but as incentives. Through what is called the practice incentive program (PIP), general practices were offered money if they voluntarily fulfilled three criteria to do with IM/IT. PIP payments covered other areas as well, after hours care, teaching, rurality and care incentives (Table 1).

The first was actually independent of computers and was given to all practices. The next two were particularly related to uptake of computers. But they were all voluntary-practices were free to apply or not, as they wish. GPs value their independence: there was no coercion involved. But the money involved was sufficient to subsidise the cost of the hardware, and this was enough for GPs to give it a go. Not surprisingly, at the end of the three year period, there were two things that the majority of GPs were doing - writing prescriptions on computer, and receiving data from pathology companies. Subsequent incentives programs have gone on to encourage data quality, recording of coded data and the use of secure messaging.

\section{Support Structure}

Significantly, the incentives were also accompanied by a support structure, through the Divisions of General Practice. Now, divisions were federally funded support structure for general practice $[19,20]$, and at that time there were 123 divisions, with a geographic spread across the country, so no GP and no practice needed to be without a division. Divisions have recently been consolidated and given a wider brief beyond general practice, and rebranded as Medicare Locals.

Each division was funded for 2001-2003 to develop a program to encourage the adoption of IT in general practice. For some, it was a dedicated officer, for others, a program spread amongst several workers. So all of a sudden there were education programs to show you how to use this new beast on your desktop. There was someone to ring if you had a problem. Some divisions ran setup services - others concentrated on clinical outcomes. Either way, there was help, and help that could be tailored to the needs - big practices, small practices, solos, GPs and staff. This sort of support is something that is often missed when public policy is developed. 


\section{In Practice Need}

However, these incentives did not arrive on virgin territory. GP systems had already started to be adopted, driven by a specific need. Computers started to arrive because Australian GPs identified a key area that computers could improve their workflow. Australian prescribing regulations are very complex, because of the structure of government subsidies [21]. Whether a drug is on prescription or not is a state regulation, but on top of that the federal government subsidizes a raft of medications. So a simple medication such as diclofenac, comes in two different strengths and three different pack sizes, as well as suppositories and injections, and is supplied by several companies under different brand names. Sometimes a drug can be prescribed easily for one condition, but requires a phone call to the responsible government agency for a different indication. Four times a year this list would be updated, with multiple changes. Remembering what pack sizes and how many repeats was confusing, and forever looking up the 'yellow' book was time consuming. So the first computer programs were little more than electronic prescribing packages, navigating the many variations.

\section{CAS and the Adoption of Practices}

The previous sections outlined the factors that brought a rapid adoption of computers, driven by three things, a need, incentives and support.

Figure 2 represents a simple framework to understand the factors that can drive any adoption process. Remembering that one of the underlying principles of CAS was that: simple agents following simple rules [can] generate amazingly complex structures. The elements of the diagram represent the attractors, rather than the rules. To further understand the process, we have to consider what the rules are-and indeed they are simple. As a professional ethic, the care of patients is a primary driver for GPs and their staff [22]. Yet, we also know that, in the context of adoption of health IT, workflow considerations are a major concern $[23,24]$. These are the rules that drive the creation of a practice work - to help a GP in the care of their patients with minimal impact on the workflow.

Viewing the computerisation in this light gives us the structure. The rules that practices follow are twofold:

- Improve my care of patients

- Minimise impact on my workflow

Following those rules creates a system in which the whole is greater than the sum of its parts. The change process then is therefore to

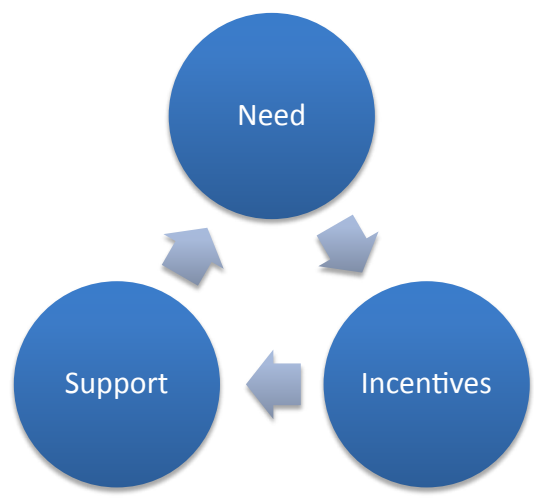

Figure 2: The adoption triangle. manipulate the attractors, be they structural, or ethical. In this case, solving the complexity of prescribing created an attractor within the practice. Externally, government was able to provide a minimal amount of money to create attractors for GPs to adopt, by providing support and money for hardware.

\section{Discussion}

The processes for adopting computers into health remains a topic of discussion - the benefits of health technology seem manifest, yet adoption rates are low, and there are many failures within the system [25]. Adoption guides still have a centralized approach - plan, deploy, and wait for outcomes [26], despite the preceding failures. The meaningful use program in the US is driving some use, but at variable rates [27]. Providing patient access is not the panacea it would seem to be [28]. Indeed, most approaches seem to be based on a 'build it and they shall come' view.

This case study from Australia provides a framework to consider how to drive uptake in any jurisdiction. The first rule of informatics is to 'start with a problem that needs solving' rather than a technology that needs to be applied [29]. However, understanding that problem is not always simple, and ensuring complete clinical input is crucial. The rules outlined above are, in part, the clinical problem we are trying to solve. Improving the care of patients whilst minimizing workflow was ready made for computers to make the process of prescribing easier. Understanding the rules magnified the power of the attractors, and spreading the encouragement across the attractors allowed for government to maximize the effect whilst minimizing the financial impact.

The cost of health programs is often hidden-immediate cost savings are not readily measurable, and indeed may not be realized until after the bulk of expenditure has occurred, and outside the timeframes of cyclical government policy. By applying the rules of CAS, as described in this paper, a means by which change and adoption of systems can be maximized at the government and policy level, often without the participants even realizing they are part of the bigger picture. First identify the rules, consider the smallest possible attractors, and let the individual agents do the work for you.

\section{References}

1. Maslow AH (1948) Higher and lower needs. J Psychol 25: 433-436.

2. Greenhalgh T, Stones $R$ (2010) Theorising big IT programmes in healthcare: strong structuration theory meets actor-network theory. Soc Sci Med 70: 1285-1294.

3. Habermas J (1985) The Theory of Communicative Action: Lifeworld and System: A Critique of Functionalist Reason. Beacon Press, Boston, USA.

4. Habermas J (1984) The Theory of Communicative Action: Reason and the rationalization of society. Beacon Press, Boston, USA.

5. Dolnick E (2011) The clockwork universe : Isaac Newton, the Royal Society, and the birth of the modern world. (1stedn) HarperCollins Publisher, New York, USA

6. Plsek PE, Greenhalgh T (2001) Complexity science: The challenge of complexity in health care. BMJ 323: 625-628.

7. Paley J (2007) Complex adaptive systems and nursing. Nurs Inq 14: $233-242$

8. Barach P, Johnson JK (2006) Understanding the complexity of redesigning care around the clinical microsystem. Qual Saf Health Care 15 Suppl 1: i10-16.

9. Reynolds CW (1987) Flocks, herds and schools: A distributed behavioural model. ACM SIGGRAPH Computer Graphics 21: 25-34.

10. Marion R (1999) The edge of organization: chaos and complexity theories of formal social systems. Sage Publications, Thousand Oaks, California, xv, pp: 357.

11. Mclnnes DK, Saltman DC, Kidd MR (2006) General practitioners' use of 
Citation: Pearce C (2013) The Adoption of Computers by Australian General Practice - A Complex Adaptive Systems Analysis. J Gen Pract 1: 121. doi: $10.4172 / 2329-9126.1000121$

Page 4 of 4

computers for prescribing and electronic health records: results from a national survey. Med J Aust 185: 88-91.

12. Bui D, Pearce C, Deveny E, Liaw T (2005) Computer use in general practice consultations. Aust Fam Physician 34: 400.

13. Jha AK, Doolan D, Grandt D, Scott T, Bates DW (2008) The use of health information technology in seven nations. Int J Med Inform 77: 848-854.

14. Jha AK, Ferris TG, Donelan K, DesRoches C, Shields A, et al. (2006) How common are electronic health records in the United States? A summary of the evidence. Health Aff (Millwood) 25: w496-507.

15. Gray BH, Bowden T, Johansen I, Koch S (2011) Electronic health records: an international perspective on "meaningful use". Issue Brief (Commonw Fund) 28: 1-18.

16. Duckett SJ (2007) The Australian health care system. (3rd edn) Oxford University Press, South Melbourne, xxi, pp: 370

17. Pearce C, Phillips C, Hall S, Sibbald B, Porritt J, et al. (2011) Following the funding trail: financing, nurses and teamwork in Australian general practice. BMC Health Serv Res 11: 38 .

18. Kidd M (2002) The computerisation of Australian General Practice 1998-2001 - what did we get for AU $\$ 15,000,000$. Informatics in primary care 10: 25-29.

19. Scott A, Coote W (2007) Whither Divisions of General Practice? An empirical and policy analysis of the impact of Divisions within the Australian health care system. Med J Aust 187: 95-99.

20. Pearce C, Shearer M, Gardner K, Kelly J, Xu TB (2012) GP Networks as enablers of quality of care: implementing a practice engagement framework in a General Practice Network. Aust J Prim Health 18: 101-104.
21. Liaw ST, Pearce CM, Chondros P, McGrath BP, Piggford L, et al. (2003) Doctors perceptions and attitudes to prescribing within the Authority Prescribing System. Med J Aust 178: 203-206.

22. Martin CM, Sturmberg JP (2005) General practice--chaos, complexity and innovation. Med J Aust 183: 106-109.

23. Shachak A, Hadas-Dayagi M, Ziv A, Reis S (2009) Primary care physicians' use of an electronic medical record system: a cognitive task analysis. J Gen Intern Med 24: 341-348.

24. Pearce C, Kumarpeli P, de Lusignan S (2010) Getting seamless care right from the beginning - integrating computers into the human interaction. Stud Health Technol Inform 155: 196-202.

25. Greenhalgh T, Stramer K, Bratan T, Byrne E, Mohammad Y, et al. (2008) Introduction of shared electronic records: multi-site case study using diffusion of innovation theory. BMJ 337: a1786.

26. Cresswell KM, Bates DW, Sheikh A (2013) Ten key considerations for the successful implementation and adoption of large-scale health information technology. J Am Med Inform Assoc 20: e9-9e13.

27. McClellan SR, Casalino LP, Shortell SM, Rittenhouse DR (2013) When does adoption of health information technology by physician practices lead to use by physicians within the practice? J Am Med Inform Assoc 20: e26-32.

28. de Lusignan S, Seroussi B (2013) A comparison of English and French approaches to providing patients access to Summary Care Records: scope, consent, cost. Stud Health Technol Inform 186: 61-65.

29. Coiera E (2013) Why e-health is so hard. Med J Aust 198: 178-179. 